\title{
Program Management at the
} National Nuclear Security Administration Office of Defense Nuclear Security:

\section{A Review of Program Management Documents and Underlying Processes}

May 2010

Pacific Northwest

NATIONAL LABORATORY

Proudly Operated by Battelle Since 1965 



\title{
DISCLAIMER
}

This report was prepared as an account of work sponsored by an agency of the United States Government. Neither the United States Government nor any agency thereof, nor Battelle Memorial Institute, nor any of their employees, makes any warranty, express or implied, or assumes any legal liability or responsibility for the accuracy, completeness, or usefulness of any information, apparatus, product, or process disclosed, or represents that its use would not infringe privately owned rights. Reference herein to any specific commercial product, process, or service by trade name, trademark, manufacturer, or otherwise does not necessarily constitute or imply its endorsement, recommendation, or favoring by the United States Government or any agency thereof, or Battelle Memorial Institute. The views and opinions of authors expressed herein do not necessarily state or reflect those of the United States Government or any agency thereof.

\author{
PACIFIC NORTHWEST NATIONAL LABORATORY \\ operated by \\ BATTELLE \\ for the \\ UNITED STATES DEPARTMENT OF ENERGY \\ under Contract DE-AC05-76RL01830
}

Printed in the United States of America

Available to DOE and DOE contractors from the

Office of Scientific and Technical Information,

P.O. Box 62, Oak Ridge, TN 37831-0062;

ph: (865) 576-8401

fax: (865) 576-5728

email: reports@adonis.osti.gov

\author{
Available to the public from the National Technical Information Service, \\ U.S. Department of Commerce, 5285 Port Royal Rd., Springfield, VA 22161 \\ ph: (800) 553-6847 \\ fax: (703) 605-6900 \\ email: orders@ntis.fedworld.gov \\ online ordering: http://www.ntis.gov/ordering.htm
}



Program Management at the National Nuclear Security Administration Office of Defense Nuclear Security:

A Review of Program Management Documents and Underlying Processes

MS Madden

May 2010

Prepared for

the U.S. Department of Energy

under Contract DE-AC05-76RL01830

Pacific Northwest National Laboratory

Richland, Washington 99352 



\section{Summary}

\section{Introduction}

The scope of this paper is to review the National Nuclear Security Administration Office of Defense Nuclear Security (DNS) program management documents and to examine the underlying processes. The purpose is to identify recommendations for improvement and to influence the rewrite of the DNS Program Management Plan (PMP) and the documentation supporting it. As a part of this process, over 40 documents required by DNS or its stakeholders were reviewed. In addition, approximately 12 other documents produced outside of DNS and its stakeholders were reviewed in an effort to identify best practices. The complete list of documents reviewed is provided as an attachment to this paper.

The document review was conducted using the current PMP (June 2009) and its description of the DNS planning, programming, budgeting, and evaluation (PPBE) as a guide for the analysis. DNS guidance for each component of the PPBEE was reviewed, conclusions about the content and quality of the guidance were drawn, and recommendations were offered.

\section{Conclusions and Recommendations}

The general conclusion resulting from the review is that the DNS program management system and its related guidance is evolving but is inadequate to produce the management capability DNS expects and responsible stewardship requires. Program management structures, processes, and tools have been adopted from previous U.S. Department of Energy (DOE) systems or developed as a result of internally identified needs or externally imposed requirements. As a result, the system is poorly integrated and hindered by inconsistent, sometimes conflicting guidance, gaps or overlaps in processes, and significant inconsistency in the way the guidance is implemented by the site offices and contractors.

In light of this conclusion, the general recommendation for DNS to consider is to commit to taking a systems approach to the update of its PMP and improvement of its PPBE-to determine specific systems requirements, to review and revise system processes so that they effectively produce and communicate required management information, to develop a set of implementing procedures and guidance documents, and to provide training to the DNS and site staff and contractor management.

The following is a summary of conclusions and recommendations identified for each phase of the PPBE process.

\section{$\underline{\text { Strategic Planning Conclusions }}$}

1. The "DNS Strategic Framework" (July 31, 2009) demonstrates a thorough understanding of and alignment with the strategic direction provided by DOE and NNSA.

2. Because DNS does not require sites to develop strategic plans, there is no evidence that the alignment DNS has achieved is carried out to the field.

\section{$\underline{\text { Strategic Planning Recommendations }}$}

1. Elevate the activities "reducing the security footprint" and "implementing technologies" to the strategy level, and develop activities that support them. 
2. Require sites to provide strategic plans that demonstrate their alignment with DNS and to identify site-specific activities they will perform in support of DNS/NNSA strategy.

\section{$\underline{\text { Tactical Planning Conclusions }}$}

1. The effectiveness of DNS program management is hindered by the lack of an integrated multi-year planning process.

\section{Tactical Planning Recommendations}

1. DNS should develop an integrated, multi-year planning process which, combined with the Future Years Nuclear Security Program (FYNSP) process, defines a five-year baseline that links operational planning with the achievement of strategic goals. Sites should be required to obtain DNS approval of their five-year plans and to review them annually and update them as appropriate. These plans should be placed under change control, and as a minimum site, Assistant Managers (AMs) should approve any changes.

\section{Operational Planning Conclusions}

1. The Program Execution Guidance (PEG) - Annual Operations Plan (AOP) process constitutes the DNS approach to management at the site level. DNS guidance states that their operational planning process is linked to strategic and tactical planning, but in practice it is not. The guidance documents at each level do not require the site planning documents to demonstrate any linkage to the higherlevel plans.

2. While it is clear that DNS would like this to be a baseline management approach, as it is currently conducted, it falls quite short. This is largely the result of a seriously flawed guidance document, the PEG. If DNS expects the sites to establish performance baselines and manage to them, DNS must require it through clear, well constructed guidance.

3. Over the years, this process has suffered from a lack of stability. Every year the PEG has been used, DNS has changed information and format requirements. The sites are then challenged to sort out the new requirements and attempt to respond in a meaningful way on a tight schedule. As a result, the products are not as high quality as they could be, and it is difficult to establish continuity of the program from year to year.

\section{Operational Planning Recommendations}

1. The AOP should be a subset of the FYNSP in a very structured sense. At a minimum, the FYNSP process should be managed under change control. During the operational planning process, if an AOP for an execution year will be different from that year's plan in the FYNSP, the changes should be identified, justified, approved at the site level, and the changes should be reflected in the FYNSP. This would ensure consistency and continuity of progress towards achieving longer-term goals.

2. The PEG must be revised in such a way that the resulting AOPs will be adequate tools for baseline management. The PEG should contain specific guidance on the work breakdown structure and the development of work packages. A milestone schedule against which progress can be measured should be required for each work package. At a minimum, the PEG should require a month-bymonth spending plan at the Budgeting and Reporting B\&R level (table and graph) that links the allocation of resources to the achievement of milestones. Templates for capturing much of this 
information already exist. They should be collected and reviewed, and the best should be modified and new templates added as necessary and used for the next iteration of the PEG - AOP process.

3. DNS should take the time to review the process to determine the necessary and sufficient set of management information it requires and the required formats. For baseline management, this information should consist of scope (defined in terms of a quantifiable, deliverable product or service), schedule (with tangible milestones), and cost (clearly linked to the deliverables and schedule). DNS should then develop the guidance document and design the AOP to ensure that it will contain the necessary information. Then, the format and content of the documents should be frozen and not changed unless directed by NNSA or other external authorities.

\section{Programming and Budgeting Conclusions}

1. Programming and tactical planning are intrinsically linked. At this stage in the planning process, the organization begins to identify and describe what actions it will take to accomplish its strategic goals. At the same time, the organization begins to develop its plan for resource allocation against the actions. DNS has not adequately linked planning and programming at the tactical (mid-term) level in the FYNSP, and this deficiency is reflected in the quality of the FYNSP data, especially in the out years.

Programming and Budgeting Recommendations

1. DNS should refine the process for developing the FYNSP with the objective of transforming the FYNSP into a true, multi-year program plan. The process should be more structurally linked to the higher-level strategic planning process and to the development of the AOPs. Establishing strong structural links in this way will facilitate DNS' oversight capability at the operational level while ensuring that the program is progressing towards the achievement of its strategic goals and vision.

\section{$\underline{\text { Progress Reporting Conclusions }}$}

1. Progress reporting across the complex is not standardized. The frequency, formality, level of detail, documentation requirements, and records management with respect to progress varies significantly from site to site. The lack of standardization has negative impacts on program management both at the site level and at the NA-70 level. Without an effective progress reporting process, accountability is lost.

\section{Progress Reporting Recommendations}

1. DNS should develop progress reporting requirements for the sites that specify, in detail, the format, content, structure, and formality of the function.

2. DNS should enforce its requirement that site-level reporting be conducted on a monthly basis.

\section{Baseline Change Control Conclusions}

1. The annual performance baseline is the most important tool DNS has to ensure that its resources are effectively applied toward the achievement of its strategic goals. An effective change control process is the only way to ensure the integrity of the baseline. The existing guidance provided to the sites on the implementation of baseline change control for the AOP is inadequate. Given the inadequacy of the guidance, the requirements for change control are implemented inconsistently across the complex. 


\section{Baseline Change Control Recommendations}

1. DNS should develop a well-structured, standardized baseline control process that ensures appropriate baseline integrity and records management across the complex. The process should include formal implementing procedures, specific information requirements, and all supporting forms and documentation.

\section{Performance Evaluation Conclusion}

1. The performance evaluation component of the DNS PPBE suffers from many of the same issues as the other components - lack of sufficient detailed guidance, lack of connection to the longer-term goals, and inconsistent application across the complex.

2. The description of the program evaluation process in the PMP does not explain how the various assessment and review results will be formulated into a final comprehensive evaluation of a site's performance.

3. The process description fails to include an explanation of how the results of the past year's evaluation should be used in the development and execution of the following year's plan.

\section{Performance Evaluation Recommendation}

1. DNS should update the program evaluation process described in the PMP with detailed guidance for contractor implementation. A description of how the various assessment and review results will be formulated into a final evaluation should be included. The guidance should also provide instructions on how the past year's performance information should be factored into the following year's plans. 


\section{Acknowledgments}

This review was commissioned by Mr. Kevin R. Leifheit, Director of Field Support within the National Nuclear Security Administration (NNSA)'s Office of Defense Nuclear Security (DNS) as part of an ongoing effort to improve DNS's program management systems and operations. Mr. Madden of Pacific Northwest National Laboratory was requested to perform an independent, objective review of DNS's program management documents and the underlying planning, programming, budgeting, and execution system in order to identify opportunities for improvement. 



\section{Contents}

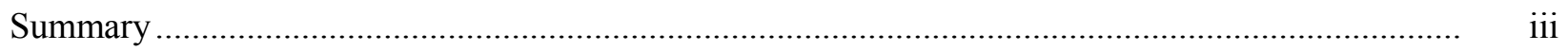

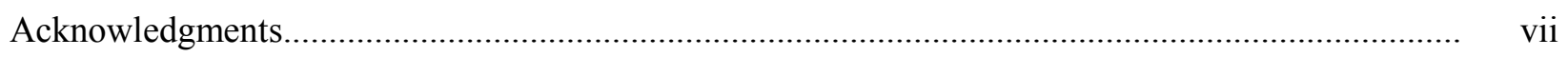

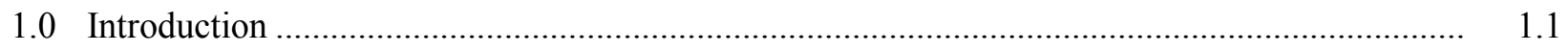

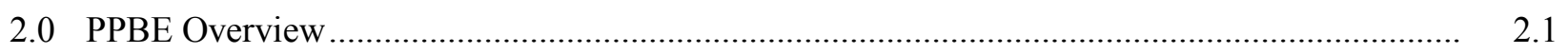

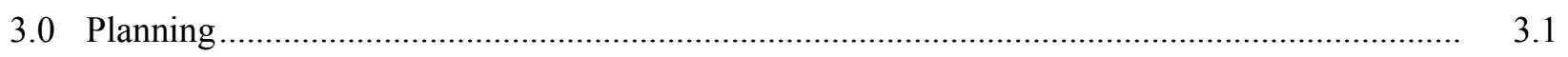

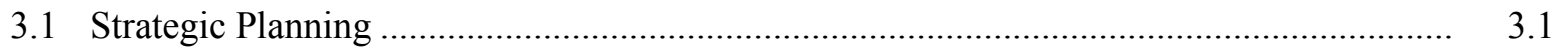

3.1.1 Strategic Planning Conclusions ...................................................................... 3.3

3.1.2 Strategic Planning Recommendations ............................................................ 3.3

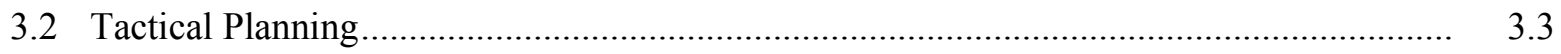

3.2.1 Tactical Planning Conclusions ….................................................................. 3.4

3.2.2 Tactical Planning Recommendations ........................................................... 3.4

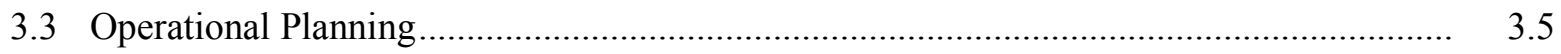

3.3.1 Operational Planning Conclusions …............................................................. 3.7

3.3.2 Operational Planning Recommendations ..................................................... 3.8

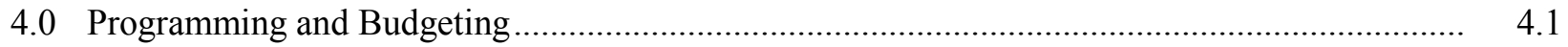

4.1 Programming and Budgeting Conclusions ................................................................. 4.3

4.2 Programming and Budgeting Recommendations ........................................................ 4.3

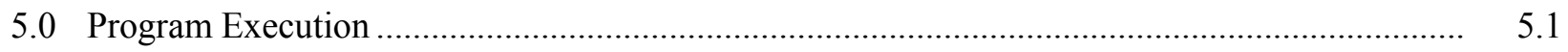

5.1 Progress Reporting ….................................................................................... 5.1

5.1.1 Progress Reporting Conclusions ............................................................... 5.2

5.1.2 Progress Reporting Recommendations ........................................................... 5.2

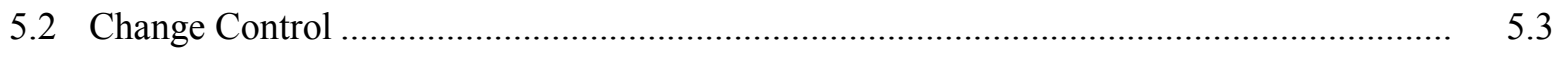

5.2.1 Baseline Change Control Conclusions ............................................................... 5.3

5.2.2 Baseline Change Control Recommendations ...................................................... 5.3

5.3 Performance Evaluation ......................................................................................... 5.3

5.3.1 Performance Evaluation Conclusion ............................................................ 5.4

5.3.2 Performance Evaluation Recommendation ...................................................... 5.4

Appendix A - List of Program Management-Related Documents Reviewed ................................... A.1 


\section{Figures}

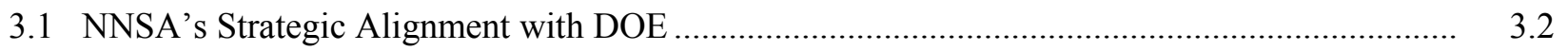

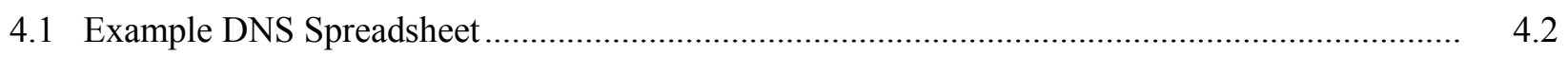




\subsection{Introduction}

The National Nuclear Security Administration (NNSA) Office of Defense Nuclear Security (DNS) has made significant progress in the last two years in establishing formality of operations with respect to program management. Since its inception, program management systems at DNS) have been evolving. Program management structures, processes, and tools have been adopted from previous U.S. Department of Energy (DOE) systems or newly developed as a result of internally identified needs or externally imposed requirements. The current Program Management Plan (PMP) published in June 2009 describes the more significant of these processes within the framework of a planning, programming, budgeting, and evaluation (PPBE) system. In addition, DNS has recently published a Policy Letter intended to institutionalize NA-70 roles and responsibilities for Governance Documentation, which includes a highlevel description of the core PPBE documentation.

The scope of this paper is to review the DNS program management documents and examine the underlying processes. The purpose is to identify recommendations for improvement and to influence the rewrite of the DNS PMP and the documentation supporting it. As a part of this process, over 40 documents required by DNS or its stakeholders were reviewed. In addition, approximately 12 other documents produced outside of DNS and its stakeholders were reviewed in an effort to identify best practices. The complete list of the documents reviewed is provided as an attachment to this paper. 



\subsection{PPBE Overview}

The purpose of a PPBE process is to support management decision making, in particular resource allocation, and to ensure that the appropriate management controls are in place to maintain responsible stewardship of the DNS budget. A properly designed and implemented PPBE provides management with a range of benefits including, but not limited to:

- A fact-based approach to ensure that decision making is consistent and aligned with organizational goals

- Explicit information about costs and progress towards achievement of goals

- Data on which to determine the costs, risks, and benefits of multiple policy decisions

- Timely and accurate information for course corrections and redirection

- Transparency, accountability, defensibility, and credibility to all aspects of program management.

Over the years, DNS has developed the basic elements of a PPBE system. The Strategic Framework (2009) represents its efforts at long-term planning, The Future Years Nuclear Security Program (FYNSP) constitutes its mid-term planning and programming, and the Annual Implementation and Annual Operations plans comprise the short-term execution plan and performance baseline. Quarterly program reviews and site change control functions are the tools for managing program execution, and the Program Evaluation Plans (PEP) are used to measure performance.

In theory, the DNS PPBE is in place and fully operational. However, in practice there are many issues, and its effectiveness is in question. In general, the system is a set of sequential, transaction-based processes. That is, DNS Headquarters issues a request for information and the sites provide a response.

For the purposes of this paper, the PPBE is analyzed as two different but integrated sets of functions separated into two major parts - Planning and Program Execution. Planning includes the predictive functions of the PPBE, Planning, Programming and Budgeting. Its focus is on the future - the organization's vision, mission, and goals and the actions it plans to take to achieve them. Program Execution is focused is on the management of site security operations. The key management functions involved during execution include progress reporting, change control, and program evaluation related to implementing the Annual Operations Plan (AOP). 



\subsection{Planning}

This section addresses the forecasting aspects of the DNS PPBE. These aspects are essentially predictive and based on facts and assumptions about the future and on plans and decisions on how DNS intends to respond to them. Therefore, this section will cover three levels of planning - strategic, tactical, and operational. During this part of the process, the organization sets the agenda to bring about its desired future state. Typically, the Strategic Plan covers the long term (usually 10 years), a tactical or multi-year plan covers the mid-term (usually 3 - 5 years), and an AOP covers the short term .

Programming and budgeting, estimating of required resources, and the delineation of timeframes for the activities identified in the plans are also discussed in the following sections.

\subsection{Strategic Planning}

As stated above, the DNS approach to strategic planning is driven by its need to be in alignment with the vision mission and goals of DOE and NNSA, respectively. In turn, site safeguards and security (S\&S) programs need to be aligned with DNS as well as with their sites' strategic direction. This review of current planning documents indicates that DNS is fairly well aligned with DOE and NNSA, but the sites' alignment is difficult to determine because DNS does not require the sites to provide strategic plans.

In November 2004, NNSA published its current Strategic Plan. In this document, NNSA aligns itself with DOE's mission and strategic goal, as illustrated in Figure 3.1. It identifies three primary strategies for meeting future $S \& S$ challenges:

1. Use an integrated program management approach with formal procedures and processes to define near- and long-term operational and performance objectives and priorities and manage, oversee, and evaluate the $S \& S$ performance of site contractors

2. Implement a corporate-wide human capital management plan to improve and sustain the quality and training of NNSA S\&S professionals

3. Focus on the use of technology to offset the reliance on costly and labor-intensive physical protection strategies. 


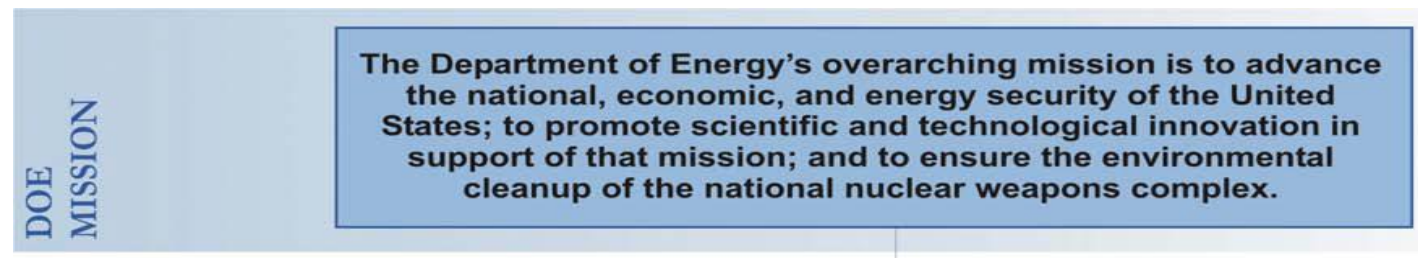

\section{Defense Strategic Goal: To protect our national security by applying advanced science and nuclear technology to the Nation's defense.}

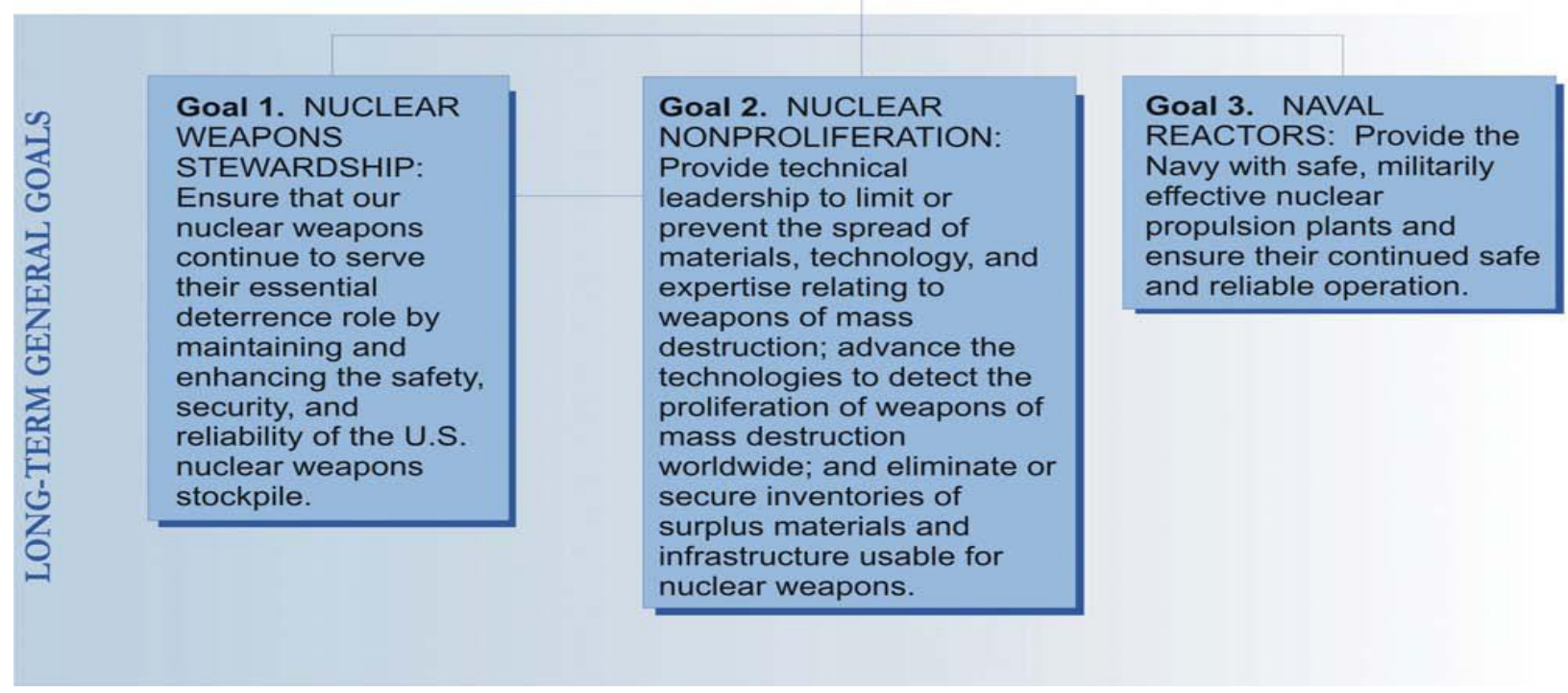

Figure 3.1. NNSA's Strategic Alignment with DOE

In October 2006, NNSA further refined its strategy in consultation the U.S. Secretary of Defense and the Nuclear Council. This strategy and the NNSA's vision for the future were articulated in NNSA's Complex 2030: an Infrastructure Planning Scenario for a Nuclear Weapons Complex Able to Meet the Threats of the $21^{\text {st }}$ Century. The thrust of this strategy is transformation of the complex from its cold-war posture into a smaller, modernized, better integrated and more efficient system for maintaining the nuclear deterrent. While there are few explicit references to $S \& S$ operations, it is clear that $S \& S$ operations must also be transformed. The most significant explicit reference to S\&S operations states the need to "apply risk-informed decision making to safety and security decision making," and to "subject rules, regulations, and major recommendations to risk-informed decision making that balances costs, benefits and risks across the spectrum of mission, safety and security needs."

In the DNS Strategic Framework (July 31, 2009), the Chief of DNS acknowledges the Complex 2030 strategy and describes its vision for the future in terms of its alignment with the broader organization. The framework is the result of their analysis of the "strategic direction the program needs to take over the next decade in order to downsize the security footprint, revitalize our aging security infrastructure, and sustain a program that is both effective and efficient." The description of the features that comprise the preferred future state addresses the key concepts of the broader strategies and further defines them in more concrete terms. 
From its analysis, DNS derived the following set of four strategies for securing the preferred future state:

1. Support the NNSA enterprise through DNS management excellence

2. Manage risk to effectively and efficiently address the spectrum of security threats

3. Recruit, sustain, and exercise the talents of people and critical skills needed to protect the enterprise

4. Provide assurance of effective and sustained performance.

These strategies, however, fail to address two key aspects of the broader NNSA strategy-downsizing and technology implementation. The framework further develops the strategies into a number of activities DNS will undertake in support of each strategy. Downsizing and technology deployment are addressed at this level, but they are significant enough (in light of NNSA's emphasis) to be strategies themselves.

\subsubsection{Strategic Planning Conclusions}

1. The DNS Strategic Framework (July 31, 2009) demonstrates a thorough understanding of and alignment with the strategic direction provided by DOE and NNSA

2. Because DNS does not require sites to develop strategic plans, there is no evidence that the alignment DNS has achieved is carried out to the field.

\subsubsection{Strategic Planning Recommendations}

1. Elevate the activities "reducing the security footprint" and "implementing technologies" to the strategy level, and develop activities which support them

2. Require sites to provide strategic plans that demonstrate their alignment with DNS and to identify site-specific activities they will take in support of DNS/NNSA strategic direction.

\subsection{Tactical Planning}

Tactical planning is the process of taking the strategic plan and breaking it down into specific, timephased activities and plans (scope, schedule, and budget) that are required to achieve the strategic goals of the organization. Tactical planning includes the process by which an organization identifies and prioritizes significant new initiatives for the achievement of strategic goals. The programming phase of the PPBE begins with this stage in the planning process.

Depending on the needs of a particular organization, the tactical plan typically covers a time span of three to five years. Schedule, budget or resource constraints often preclude completion of significant, transformative actions within a single year. Tactical or multiyear plans enable the organization to spread these types of activities across fiscal years and fit them into time periods when funding and resources are available. Multiyear plans also facilitate an organization's ability to track progress and resource utilization across a fiscal year and make timely adjustments as necessary. It is important that tactical plans be reviewed annually and modified appropriately to ensure they are aligned with the strategic plan and that all activities are still required and aimed at moving closer to the goals defined in the strategic plan. 
The DNS PMP indicates that the FYNSP process "includes more specific multiple-year programmatic requirements, performance and budget targets for the planning period and serves as the bridge between the Strategic Plan and the Annual Operating Plan." However, past guidance has not called on the sites to provide information related to work planning but focused exclusively on budget data. The current guidance (January 2010) requests work planning information (assumptions, general plant projects and line-item projects, site priorities, challenges, etc.), but does not require the sites to provide an integrated multiyear plan that lays out a coherent, time-phased program baseline (scope, schedule, and budget) or that describes the linkages between the DNS Strategic Plan and the site's AOP. As in the past, the focus of the FYNSP was on the budget data.

Additionally, a number of other required plans do cover multiple years but they are not integrated and do not comprehensively cover the entire program. These plans include:

- The Ten-Year Site Plans

- The Graded Security Policy Implementation Plans

- The Site Safeguards and Security Plans

- Physical Security Technology Plans

- Numerous other implementation plans (Materials Control and Accountability (MC\&A) Plan, Homeland Security Presidential Directive -12 (HSPD-12), Tactical Response Force (TRF) Plans, corrective action plans (CAPs), etc.).

These plans ought to contribute information into the FYNSP process, and requirements identified in them should be reflected in the FYSNP documentation.

For many reasons, the lack of a well integrated tactical planning process represents a serious gap in the planning for the achievement of strategic goals. Without the multiyear plan, there is no explicit link between the activities in the AOP and the DNS Strategic Plan, and the result is that each AOP becomes a stand-alone effort. Programmatic decision making is disconnected. Without a five-year action plan, the basis for the FYNSP is ambiguous (see Section 4) and proposed budget requests are more difficult to defend.

The FYNSP process is discussed in greater detail in Section 4.

\subsubsection{Tactical Planning Conclusions}

1. The effectiveness of DNS program management is hindered by the lack of an integrated multiyear planning process.

\subsubsection{Tactical Planning Recommendations}

1. DNS should develop an integrated multiyear planning process which, combined with the FYNSP process, defines a five-year baseline that links operational planning with the achievement of strategic goals. Sites should be required to get DNS approval of their five-year plans and should be required to review them annually and update them as appropriate. These plans should be placed under change control, and as a minimum, site Assistant Managers (AM's) should approve any changes. 


\subsection{Operational Planning}

Operational planning represents the near-term phase (usually one year) of an integrated planning process. The operational plan is a subset of a multiyear plan that describes short-term actions for achieving milestones that contribute to the achievement of longer-term goals and explains how, or what portion of, a multiyear plan will be put into operation during a given operational period. The operational plan should describe in detail the performance baseline for the execution year. This baseline should include a description of the scope of work to be performed; a schedule over which the work will be conducted, including interim milestones against which progress can be evaluated; and a time-phased budget that is unambiguously linked to the scope and schedule.

The core documents that comprise the process are the Annual Program Execution Guidance and the AOP. However, many other DNS documents contribute to the process . The most significant include: The NNSA Strategic Plan/Planning Guidance, DNS Strategic Plan/Strategic Framework, the FYNSP, results from DNS Quarterly and Annual Program Reviews, cost reviews, contractor self-assessments, site office surveys, and external reviews.

The PMP describes the program execution guidance (PEG) as follows: "The PEG is issued annually by NA-70 as the basis for development of the AOP for each NNSA site for the upcoming fiscal year. The PEG provides both funding guidance and enterprise-wide high-level performance objectives and schedules to be included in the individual site AOPs for the upcoming fiscal year."

The PEG has been evolving and has contained different guidance every year. A review of the 2010 PEG (June 29, 2009) reveals the following contents:

- Cover letter that provides general information about the PEG, its drivers and due dates, and instructions for submission of the AOP

- Table 1, which restates "FY 2010 Strategic and Performance Objectives" from the Strategic Framework

- Table 2, "Performance Objectives for Program and Resource Guidance," which provides an example of the performance information provided in the FY2010 Performance Implementation Plan

- Table 3, "DNS FY 2010 Site Allocations," which contains the site by site FY 2010 allocation totals.

Attached to the cover letter are the following documents:

- The DNS Program Management Plan (June 2009)

- Attachment C, Summary/Task Description Sheets

- The FY 2010 Performance Implementation Plan Spreadsheet (May 21, 2009).

As a guidance document, this 2010 PEG is seriously flawed internally, and it tends to highlight the flaws of the rest of the DNS planning process. There is no way that anyone unfamiliar with DNS and the AOP process could use this document to produce anything useful as a management tool. For example, the second sentence in paragraph 3 of the letter states, "A performance-based AOP/Budget is focused on demonstrating successful accomplishment of complex-wide security performance outcomes." It is 
difficult to determine what that sentence means, let alone use it as guidance for developing an AOP. In essence, it says that a site's annual plan must prove accomplishment of complex-wide security performance outcomes.

In the next paragraph, the second sentence states, "Each NNSA Site Office will publish and AOP with a commensurate spend plan and contractor PEP to meet the overarching PEG Strategic Objectives and Performance Objectives" Again, this guidance is directing a single site to develop a plan to accomplish "overarching strategic objectives" in one year, with one year's budget, which by the definition of "strategic" is technically impossible. Similar examples of confusing language can be found throughout the document.

The DNS Program Management Plan is the first attachment to the letter. However, the letter does not identify it as an attachment and does not provide any information as to how it should be used in the development of the AOP. Likewise, Attachment C, Summary/Task Description Sheets, is not referenced in the letter, and there are no instructions on how they are to be used in the development of the AOP.

The letter does reference Annex 1 (FY 2010 Performance Implementation Plan). It states that "The complete set of FY 2010 PEG Strategic Objectives, Performance Objectives Performance Measures and Performance Targets are provided in Annex 1." The guidance with respect to the use of Annex 1 in the development of the AOP states "All Site Offices are required to address the DNS Strategic Objectives and Performance Criteria listed in Annex 1." This statement is too ambiguous to serve as guidance. How is the word "address" to be interpreted? It could mean that Site Offices should comment on the DNS Strategic Objectives and Performance Criteria listed in Annex 1. It could mean that the Site Offices should explain how the work they propose to do relates to the DNS Strategic Objectives and Performance Criteria listed in Annex 1. It could also mean that the Site Offices should develop specific work scope, schedules, and budgets to accomplish the DNS Strategic Objectives and Performance Criteria listed in Annex 1. In addition, the spreadsheet provided does not have a list of Performance Criteria to address. It does list DOE Strategic Objectives, DNS Strategic Objectives, Program Improvement Plan (PIP) Performance Objectives, PIP Performance Measures, and PIP Performance Targets. Are the Site Offices to address only the DNS Strategic Objectives and Performance Criteria?

The AOP is described in the PMP as follows:

"Using a work breakdown structure (WBS), the AOP is developed by the site contractor, to define the work scope to be executed during the upcoming fiscal year. Each site AOP includes work scope (operating and capital), milestones, schedule, performance measures, estimated full-time equivalents (FTE) and costs, including overtime, for the fiscal year. The AOP process incorporates the use of Task Description Sheets (TDS) for each of the security functional areas and Summary Description Sheets (SDS) that rollup the individual functional areas into a summary security performance baseline for the site."

"The approved AOP represents the site's annual security performance baseline and is governed by a formal site change control system."

This description captures the key concepts of an annual baseline - scope, schedule, budget, and change control. However, neither the PMP nor the PEG provides guidance to the sites as to what the 
AOP should specifically contain and what the format should look like. The PMP states that sites should incorporate the summary and task description sheets into the AOP process and provide a description of the information called for in these forms. The PEG includes examples of the forms but the forms do not match the description in the PMP.

The use of forms is a good idea for achieving standardization of the information from the sites. However, the forms provided in the PEG do not contain the fields required to adequately communicate an annual performance baseline. It appears that the "Functional Task Summary" field is intended to be the scope statement. The statements provided do not describe the work that must be accomplished over the year but are simply statements of what costs apply to the B\&R code. In a performance baseline, the scope statement must describe the work to be done in a way that the work can be linked to a schedule and a time-phased budget so that progress toward the completion can be measured and evaluated.

The next two fields, "Priorities/Areas of Interest" and "New Initiatives" are not technically part of a baseline. It may be information DNS is interested in having, but it has no value in the baseline management.

"Estimated Costs" is a required baseline field. The form, however, only allows for the total cost estimated, and there is no way to show the spend plan for the year. That is, there is no ability to link the costs to the performance of the work. For cost information to be useful in baseline management it must be linked to work scope and schedule.

In past years, the PEG has required milestone/schedule information to be provided in the AOP, either on the Task Description Sheets or elsewhere in the document. The FY 2010 PEG does not explicitly call for schedule information. Without schedule information the baseline is incomplete.

The FY 2010 AOPs were not available for this review. However, reviews of past AOPs revealed a substantial variation in the content and format of the AOPs submitted by the sites and even between the years at any given site, making site-to-site comparisons difficult. None of the AOPs reviewed provided complete and actionable performance baseline information.

\subsubsection{Operational Planning Conclusions}

1. The PEG - AOP process constitutes the DNS approach to management at the site level. DNS guidance states that its operational planning process is linked to strategic and tactical planning, but in practice it is not. The guidance documents at each level do not require the site planning documents to demonstrate any linkage to the higher-level plans.

2. While it is clear that DNS would like this to be a baseline management approach, as it is currently conducted, it falls quite short. This is largely the result of a seriously flawed guidance document, the PEG. If DNS expects the sites to establish performance baselines and manage to them, DNS must require it through clear, well constructed guidance.

3. Over the years, this process has suffered from a lack of stability. Every year the PEG has been used, DNS has changed information and format requirements. The sites are then challenged to sort out the new requirements and attempt to respond in a meaningful way on a tight schedule. As a result, the products are not as high-quality as they could be, and it is difficult to establish continuity of the program from year to year. 


\subsubsection{Operational Planning Recommendations}

1. The Annual Operations Plan should be a subset of the FYNSP in a very structured sense. At a minimum, the FYNSP process should be managed under change control. During the operational planning process, if an AOP for an execution year will be different from that year's plan in the FYNSP, the changes should be identified, justified, approved at the site level, and the changes should be reflected in the FYNSP. This would ensure consistency and continuity of progress towards achieving longer-term goals.

2. The PEG must be revised in such a way that the resulting AOPs will be adequate tools for baseline management. The PEG should contain specific guidance on the work breakdown structure and the development of work packages. A milestone schedule against which progress can be measured should be required for each work package. At a minimum, the PEG should require a month-bymonth spend plan at the B\&R level (table and graph) that links the allocation of resources to the achievement of milestones. Templates for capturing much of this information already exist. They should be collected and reviewed, the best should be modified, and new templates added as necessary and used for the next iteration of the PEG - AOP process.

3. DNS should take the time to review the process to determine the necessary and sufficient set of management information it requires and the required formats. For baseline management, this information should consist of scope, schedule, and cost. DNS should then develop the guidance document and design the AOP to ensure that it will contain the necessary information. Then, the format and content of the documents should be frozen and not changed unless directed by NNSA or other external authorities. 


\subsection{Programming and Budgeting}

Programming is the effort of translating the goals and objectives of the organization (i.e., requirements) into finite actions with resources applied. Programming is the stage when the organization considers alternative approaches to accomplishing its goals and objectives. The most important task of programming is to integrate all the different requirements into a balanced program. This program balancing becomes difficult when it must be achieved within constrained resources.

Programming and budgeting are very similar activities. They differ in the timeframe covered and the precision with which they are conducted. Generally, programming covers a period of two to five years and resource estimates are high-level. Budgeting typically covers one to two years, and resource requirements are calculated to the level of detail by which they will be managed.

The FYNSP process constitutes NNSA's programming effort. The current DNS FYNSP is an annual, rolling summary of site-level planning and resource data. The process for developing the FYNSP consists of:

- DNS develops and disseminates the data call (FYNSP Data and Resource Request, FY+6) to the Site Office Assistant Managers (AMs) for Security and Safeguards who pass it on to the site contractors

- Site contractors provide the planning and resource data to the site AMs for review and approval

- On approval by the AM, the data are submitted to DNS

- DNS reviews and compiles the information, which is then submitted to the NNSA Administrator for inclusion in the NNSA budget request to Congress

- Congress reviews the submissions and provides NNSA with the approved funding levels for coming fiscal year plus five out years. These "pass backs" contain the official fiscal year budgets and outyear planning targets for DNS.

The primary documents that drive this stage of the planning process are the DNS data call guidance and the site submissions. Other documents (and their associated processes) should influence the content, and these include:

- Current NNSA and DNS strategic planning guidance

- The prior year's FYNSP

- The results of the prior year performance evaluation

- The results of prior year audits and assessments and approved corrective action plans.

The FY2012-2016 Program and Resource Guidance is the current version of the FYNSP guidance. As discussed in Section 3, Planning, this document is almost entirely focused on budget data preparation. The sites are required to identify a prioritized set of activities for which they are to supply resource requirements (funding and staffing) for the current year, the coming execution year, and the next 5 out years. Figure 4.1 is an example of the spreadsheet DNS has developed to capture this information. 


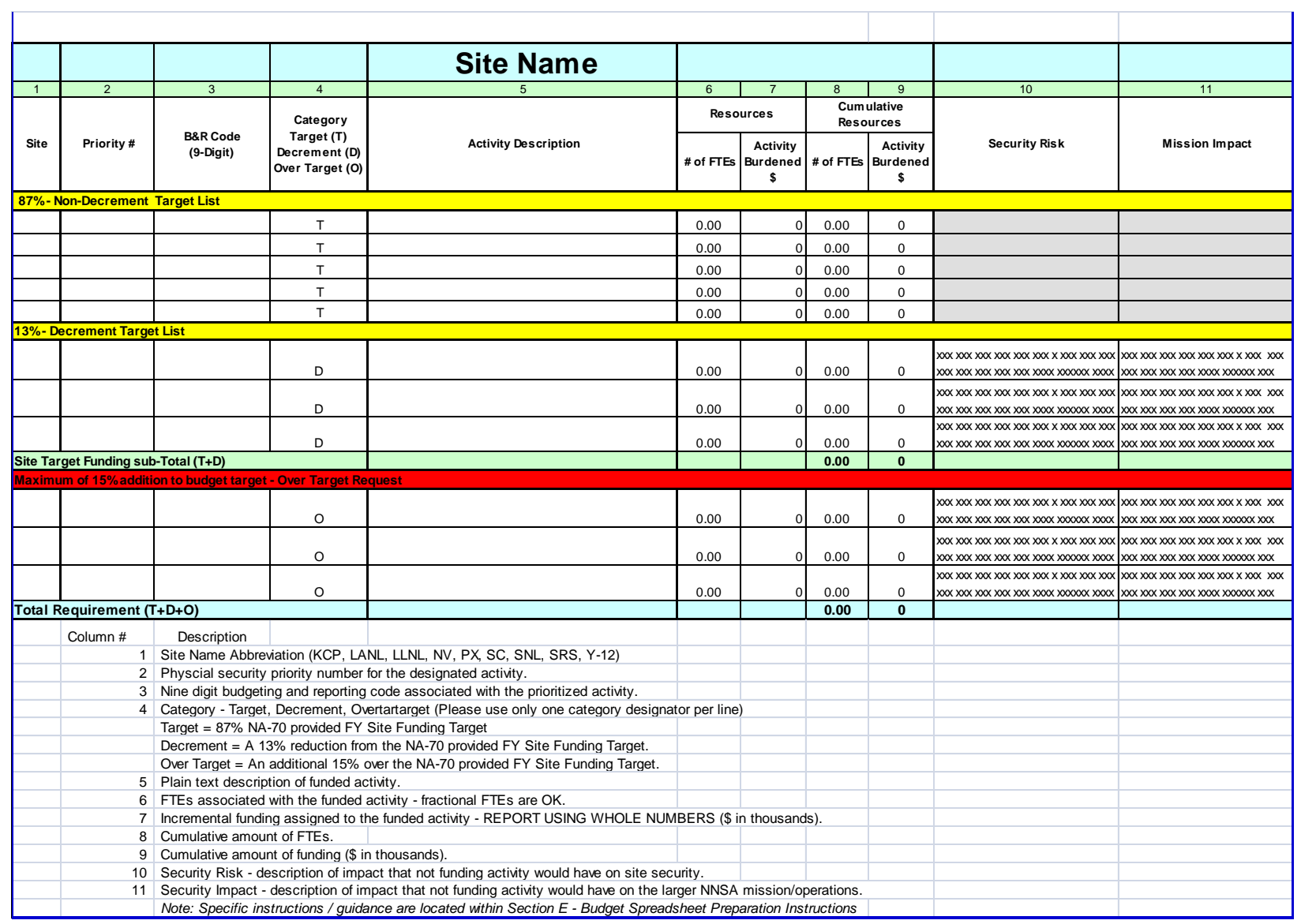

Figure 4.1. Example DNS Spreadsheet

This spreadsheet has been the most stable tool in the DNS process. While it has evolved over the years, the changes have been small and the general concept has remained intact. Therefore, the sites are fairly comfortable using it.

Changes in this year's version, for example, include the addition of the "Security Risk" and "Mission Impacts" columns. This information has been requested in the past, but this year it is included on the spreadsheets. In addition, a supplemental spreadsheet is required for protective forces detail.

As a programming/budgeting tool, the spreadsheet works fairly well, though there are some operational problems. The sites tend to be inconsistent in their activity descriptions and in their application of the B\&R and sub-B\&R codes. There is still confusion over "in-target" and "over-target;" for example, how to split an activity into both in-target and over-target components or how to carry activities in over-target across out years.

The most significant shortcoming of this aspect of the DNS process is that it is disconnected from strategic planning on one hand and from the AOP on the other. The activity descriptions presented in FYNSP spreadsheets are at such a granular level of detail it is very difficult to trace them to strategic goals. In addition, the process does not seem to have the requisite feedback loops between actual operations and tactical planning and between tactical planning and strategic planning. Only in an ideal world can it be true that all the work planned for an execution year is completed precisely on schedule 
and within budget. Variances usually occur. The DNS process does not have a mechanism to ensure that the variances are accounted for correctly. For example, if an activity is not completed within a given FY and funding is available to finish the work, those funds should be carried over to the next fiscal year and applied to the completion of the activity. The current DNS process does not account for carryover in the FYNSP process.

Another significant shortcoming that arises from the disconnectedness issue is that for the most part, the out-year budgets are calculated using an escalation factor on the activities in the execution year and are not the results of a true planning process. As stated earlier, it is not necessary for the out years to be programmed with the same precision as an execution year; however, DNS should require a more structured, realistic approach to planning for the out years than simple escalation.

\subsection{Programming and Budgeting Conclusions}

1. Programming and tactical planning are intrinsically linked. At this stage in the planning process, the organization begins to identify and describe what actions it will take to accomplish its strategic goals. At the same time, the organization begins to develop its plan for resource allocation against the actions. DNS has not adequately linked planning and programming at the tactical (mid-term) level in the FYNSP, and this deficiency is reflected in the quality of the FYNSP data in the out years.

\subsection{Programming and Budgeting Recommendations}

1. DNS should refine the process for developing the FYNSP. The process should be more structurally linked to the higher-level strategic planning process and to the lower -level annual operations planning. Establishing strong structural links in this way will facilitate DNS's ability to manage at the operational level while ensuring that the program is progressing towards the achievement of its strategic goals and vision. 



\subsection{Program Execution}

The previous phases of the PPBE are conducted in the unreal, hypothetical world of planning and their products - plans, budgets, and schedules are based on assumptions that represent the planners' best guess at the time. Program execution takes place in the real world, and it is only through implementation of the approved baselines that the success of the previous phases can be determined. That is, were the expected results achieved within the approved schedule for the estimated cost?

Invariably during execution issues arise - priorities change, incidents occur, etc., that were unforeseen. These are facts of life that drive the need to make changes to plans. The PPBE must be capable of responding to these issues in a structured way that is realistic, logical, defensible, and traceable. It is also important to ensure that information about the changes is fed back into the other ongoing phases of the PPBE.

Upon approval of the AOP and receipt of the work authorization for the fiscal year, the DNS site offices and site contractors begin to implement the work scope defined in the AOP. At this point, the program management functions of progress reporting, change control, and program evaluation are initiated. Each of these functions is discussed in the following sections.

\subsection{Progress Reporting}

The approved AOP constitutes the performance baseline for the execution year. It defines the scope of work to be accomplished, the schedule by which it will be accomplished, and estimate of what it will cost to accomplish. During program execution, it is required that management at the contractor, site, and DNS levels be provided with timely, accurate, and actionable information concerning the accomplishment of the work. Progress reporting is the process for providing that information. Typically, progress reporting is conducted at the operational level on a monthly basis to coincide with standard costaccounting practices.

The DNS PMP refers to progress reporting in Section 6.0, Performance Evaluation. This section refers to it as program reviews. The PMP requires two levels of review, monthly at the site office level and quarterly at the NA-70 level.

Site offices are directed to "conduct monthly program reviews of the contractor's performance against the approved AOP baseline. Assessments address current AOP status against costs, scope, manpower and schedule baselines, variances requiring attention, status of contractor commitments, progress against award fee performance incentives, and new and emerging issues that need to be addressed." Beyond this reference in the PMP, DNS does not provide the sites with other guidance for monthly progress reporting.

Currently, the format, content, and level of formality for progress reporting are not standardized across the DNS sites. There are significant differences from site to site with respect to level of detail and specificity of the information provided, the qualitative and quantitative nature of the information, and the level of contractor/federal interaction in the determination of progress against the approved plans. Some sites comply with the requirement for monthly reviews while some do not. 
The lack of standardization affects DNS program management in several ways. First is in the degree to which the site offices can exercise their oversight of contractor operations. At sites where progress reviews are formalized and rigorous, site office staffs are better equipped to make programmatic decisions, assume responsibility for site operations, and communicate with NA-70 staff. At sites where progress reporting is less formalized and rigorous, site office staff and NA-70 staff must rely more heavily on their site contractors.

According to the PMP, NA-70 "conducts annual Program Reviews at each NNSA site to evaluate the contractor's overall security program status and specific objectives delineated in the AOP. In these sessions, NA-70 assesses overall program performance, progress against PEG and site-specific objectives, other critical contractor performance issues and potential cost and schedule variances. The format/content of the reviews should follow the structure/approach used in the monthly program review between the contractor and the site office."

As it is written in the PMP, this statement is slightly inaccurate. For the last two or three years, DNS has provided specific guidance on the format, content, and structure for their quarterly reviews, and these reviews are usually conducted at one site with representatives from all site offices and contractors in attendance. Additionally, the fourth quarterly review is usually a retrospective on the entire fiscal year.

The Quarterly Program Review process as conducted is consistent with standard government and industry practices. The reporting of actual cost versus budgeted cost and the explanation of variance is a standard practice, and for the most part, the sites provide accurate cost data. The discussion of accomplishments and challenges is useful to DNS in that it provides contextual information related to site security operations.

However, the lack of standardization in reporting on certain key attributes at the site level referenced above clouds the picture somewhat. For example, consider the use of the stoplight charts to represent progress against AOP milestones. What does green mean when some sites are tracking 80 to 100 milestones and others are tracking 8 to 10 , and some sites are using quantitative measures to determine progress and others are using purely subjective means? Such discrepancies make it difficult to judge the "health" of one site relative to the others. Furthermore, the discrepancies described in this example have significant implications with respect to evaluation for award fee, as discussed in Section 5.3, Performance Evaluation.

\subsubsection{Progress Reporting Conclusions}

1. Progress reporting across the complex is not standardized, and the lack of standardization has negative impacts on program management both at the site level and at the NA-70 level.

\subsubsection{Progress Reporting Recommendations}

1. DNS should develop progress reporting requirements for the site that specifies, in detail, the format, content, structure and formality of the function

2. DNS should enforce its requirement that site-level reporting be conducted on a monthly basis. 


\subsection{Change Control}

During the execution of the AOP, numerous unforeseen events can occur that justify changes to the baseline. The baseline change control process is the mechanism by which changes to the performance baseline can be processed in a structured, systematic manner that ensures authorization by the appropriate management level and ensures timely and complete communication to all stakeholders in the process.

The purpose of a change control process is to ensure that:

- The cost, schedule, and technical impacts of the proposed changes are developed and considered by all affected parties

- The collected evaluations are considered in the approval or rejection of the proposed changes

- All affected parties are informed of proposed changes and their dispositions

- Baseline documentation is controlled and updated as appropriate to reflect approved changes

- Action on proposed changes occurs deliberately, but without undue delay and without interfering disproportionately with project progress.

The DNS PMP contains a lengthy description of its change control process. It contains a table of change control approval thresholds and a summary of the information that should be included in a baseline change proposal. It also references DOE Order 430.1B Real Property Asset Management and "supplemental DOE guidance" as a resource for change control on line item projects. Other than this information, the PMP guidance on the baseline change control process does not provide much help for the sites that must implement it. It appears that sites must develop and manage change control on their own.

\subsubsection{Baseline Change Control Conclusions}

1. The annual performance baseline is the most important tool DNS has to ensure that its resources are effectively applied towards the achievement of its strategic goals. An effective change control process is the only way to ensure the integrity of the baseline. The existing guidance provided to the sites on the implementation of baseline change control for the AOP is inadequate. Given the inadequacy of the guidance, the requirements for change control are implemented inconsistently across the complex.

\subsubsection{Baseline Change Control Recommendations}

1. DNS should develop a well-structured, standardized baseline control process that ensures appropriate baseline integrity and records management across the complex. The process should include formal implementing procedures, specific information requirements, and all supporting forms and documentation.

\subsection{Performance Evaluation}

The DNS PMP provides an overview of the Performance Evaluation Process. The process consists of a set of reviews and assessments that includes the monthly site office program reviews of progress against the AOP baselines, the quarterly NA-70 program and budget reviews, contractor self assessments, and 
independent oversight reviews and assessments. Each of these reviews is briefly described but there is little guidance for how these reviews are to be conducted and no guidance as to format and content.

DOE Order 470.4-1 chg 1 provides additional guidance for the conduct self assessments, and there are references in other orders as well.

An important part of the evaluation process that is not discussed in the PMP or in any of the other documents reviewed is the methodology by which the various reviews and assessments are compiled into a single overall assessment.

A second important aspect of an evaluation process in a PPBEs that appears to be missing in the DNS documentation is how the evaluation information for a particular execution year is used in the development of subsequent year planning, programming, and budgeting.

The PMP also discusses the use of performance information in the determination of award fees, which is not really a part of a PPBE process.

\subsubsection{Performance Evaluation Conclusion}

1. The performance evaluation component of the DNS PPBE suffers from many of the same issues as the other components - lack of sufficient detailed guidance, lack of connection to the longer-term goals, and inconsistent application across the complex

2. The description of the Program Evaluation Process in the PMP does not explain how the various assessment and review results will be formulated into a final comprehensive evaluation of a site's performance

3. The process description fails to include an explanation of how the results of the past year's evaluation should be used in the development and execution of the following year's plan.

\subsubsection{Performance Evaluation Recommendation}

1. DNS should update the program evaluation process described in the PMP with detailed guidance for contractor implementation and, a description of how the various assessment and review results will be formulated into a final evaluation. The guidance should also provide instructions on how the past performance information should be factored into the following year's plans. 


\section{Appendix A}

\section{List of Program Management-Related Documents Reviewed}





\section{Appendix}

\section{List of Program Management-Related Documents Reviewed}

\section{A.1 U.S. Department of Energy, National Nuclear Security Administration, Office of Defense Nuclear Security, and Field Site Documents}

U.S. Department of Energy Implementation Plan: National Nuclear Security Administration, January 1, 2000.

NNSA Strategic Plan, November 2004.

Complex 2030, An Infrastructure Planning Scenario for a Nuclear Weapons Complex Able to meet the Threats of the $21^{\text {st }}$ Century, October 23, 2006.

Annual Operations Plans

- LANL FY08, FY09, FY10

- Pantex FY08

- Y-12 FY08

Program Execution Guidance, FY08, FY09, FY10.

DNS Program Management Plan, June 2009.

Site Annual Performance Evaluation Plan, LANL FY2008, 2009.

FYNSP Data \& Resource Requirement (FY+6) Data Request, FY08, FY09, FY110.

DNS Strategic Plan.

DNS Strategic Framework, 2009.

Site Safeguards and Security Plan, LANL FY09.

Graded Security Policy Implementation Plan, LANL FY09

Design Basis Threat Policy Implementation Plan, LANL FY07.

Corrective action plans, LANL FY09.

Safeguard and Security (S\&S) Evaluation and Performance Assurance Program, 2009.

Physical Security Technology Management Plan, November 2009. 
DNS HQ Safeguard and Security (S\&S) Self Assessment Plan CY 09, June 2009.

FYNSP Response, LANL FY08, FY09.

PPBEE Presentation; Peterson, Brad , 2009.

FYNSP 2011 -15 HQ Budget Review Briefing, April 9, 2009.

Quarterly Program Review Guidance, FY08, FY09.

Quarterly Program Review Presentations, FY08, FY09.

Annual Program Review Guidance, FY08, FY09.

Annual Program Review Presentations, FY08, FY09.

Quarterly contractor evaluation, LANL FY08.

Survey Reports, LANL FY07, FY08.

Self Assessment Reports, LANL FY08, FY09.

S\&S Functional Management Plan (FMP), Appendix B Update, June 2009.

DNS Security Functions, Responsibilities, and Authorities Manual (SFRAM), May 2007 (currently being updated).

DNS Homeland Security Presidential Directive-12 (HSPD-12) Program Management Plan, December 2009.

DNS Technical Qualification Program (TQP) Implementation Plan, October 2008.

DNS Security Lessons Learned Center Handbook/Users' Guide Version 3, March 2009.

DNS Presidential Budget Submissions, FY08, FY09, FY10.

\section{A.2 External Documents}

Strengthening Homeland Security: Reforming Planning and Resource Allocation; Williams, Cindy, Massachusetts Institute of Technology, 2008.

Strategic Use of Analytics In Government; Davenport, Thomas, and Jarvenpaa, Sirkka, IBM Center for the Business of Government, 2008.

Moving toward Outcome-Oriented Performance Measurement Systems; Callahan, Kathe and Kloby, Kathryn , Rutgers University, 2008. 
Linking Performance and Budgeting: Opportunities in the Federal Budget Process; Joyce, Philip G., The George Washington University, 2003.

Performance Budgeting: How NASA and SBA Link Costs and Performance; Blanchard, Lloyd, IBM Center for the Business of Government, 2006.

Department of Defense Planning Programming Budgeting and Execution (PPBE) Process; US Army War College, 2006.

PPBS to PPBE: A Process or Principles? Grimes, Colonel Steven R, US Army War College, 2008

The Critical Success Factor Method: Establishing a Foundation for Enterprise Security Management; Caralli, Richard A. Carnegie Melon University, 2004. 



\section{Distribution}

No. of

Copies

\# Name

Organization

Address

City, State and ZIP Code

\# Organization

Address

City, State and ZIP Code

Name

Name

Name

Name

Name (\#)

\# Name

Organization

Address

City, State and ZIP Code
No. of

Copies

\# Foreign Distribution

\# Name

Organization

Address

Address line 2

COUNTRY

\# Local Distribution

Pacific Northwest National Laboratory

Name

Name

Name

Name

Name
Mailstop

Mailstop

Mailstop

Mailstop

(PDF) 




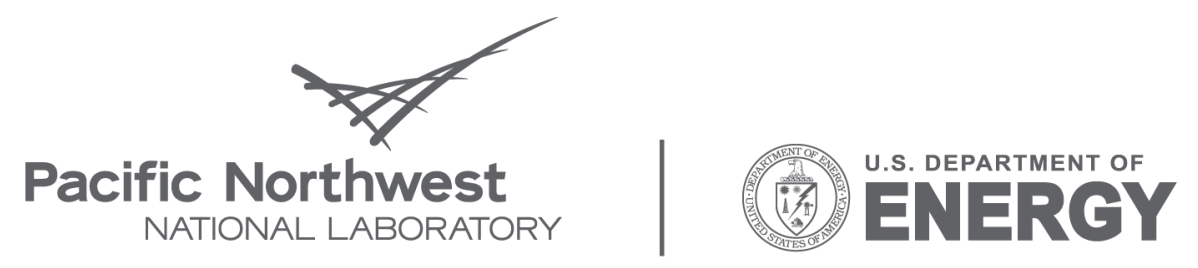

Proudly Operated by Battelle Since 1965

902 Battelle Boulevard

P.O. Box 999

Richland, WA 99352

1-888-375-PNNL (7665)

www.pnl.gov 